\title{
Assessment Postpartum Glucose Status among Women with Gestational Diabetes: Experience of a Sub-Saharan African Endocrinology Department
}

\author{
Ngoné Diaba Diack¹, Nafy Ndiaye1, Aminata Mbaye1, Mamadou Ba1', Khadidja Samb1, \\ Pape Momar Guisse1, Coumba Faye1, Amy Seye1, Yakham Mohamed Leye1, \\ Abdoul Aziz Diouf², Alassane Diouf², Abdoulaye Leye ${ }^{1}$ \\ ${ }^{1}$ Endocrinology-Diabetology Department, Teaching Hospital of Pikine, Dakar, Senegal \\ ${ }^{2}$ Obstetrics and Gynécology Department, Teaching Hospital of Pikine, Dakar, Senegal \\ Email: diackngone@gmail.com
}

How to cite this paper: Diack, N.D., Ndiaye, N., Mbaye, A., Ba, M., Samb, K., Guisse, P.M., Faye, C., Seye, A., Leye, Y.M., Diouf, A.A., Diouf, A. and Leye, A. (2020) Assessment Postpartum Glucose Status among Women with Gestational Diabetes: Experience of a Sub-Saharan African Endocrinology Department. Journal of Diabetes Mellitus, 10, 124-131.

https://doi.org/10.4236/jdm.2020.103011

Received: May 6, 2020

Accepted: June 26, 2020

Published: June 29, 2020

Copyright ( 2020 by author(s) and Scientific Research Publishing Inc. This work is licensed under the Creative Commons Attribution International License (CC BY 4.0).

http://creativecommons.org/licenses/by/4.0/ (c) (i) Open Access

\begin{abstract}
Background: Women with gestational diabetes mellitus (GDM) have a significantly increased risk for developing type 2 diabetes after delivery. The purpose of this study was to determine the postpartum glycemic status among women with GDM in an Endocrinology-Diabetology department in Sub-Saharan Area. Methods: It was a prospective cohort study conducted between January 1, 2013, and July 31, 2018 (over period of 5 years and 7 months) at Pikine National Hospital, Dakar, Senegal. Postpartum glucose status was evaluated at least 6 weeks post-partum among women with history of GDM according to IADPSG criteria. The glycemic status after delivery was pointed referring to 2006 WHO criteria. Results: Overall 53 patients were included in this study. Fasting plasma glucose was performed as a screening test in $94 \%$ of the cases. A type 2 diabetes after GDM as diagnosed in 6 patients, accounting for a prevalence of $11.32 \%$. An Impaired Fasting Glucose (IFG) was revealed in 5 patients $(9.43 \%)$. The patients underwent a screening test in the first year after delivery in $54.70 \%$ of the cases, over a half of whom during the post-partum period range from the $6^{\text {th }}$ to the $12^{\text {th }}$ week. Insulin usage during pregnancy was statistically correlated with the occurrence of postpartum diabetes. Conclusion: Diabetes prevention and early diagnosis require a glycemic status monitoring among women with history of GDM.
\end{abstract}

\section{Keywords}

Gestational Diabetes Mellitus, Postpartum Glucose Status, Type 2 Diabetes, Africa, IADPSG 


\section{Introduction}

Gestational diabetes mellitus (GDM) is a major public health problem [1]. Previously considered a disease of affluent developed countries, it has become more common in developing countries [2]. The prevalence of GDM in the sub-Saharan African region is $14.28 \%$ using current international diagnostic criteria [1].

Women with GDM have a significantly increased risk for developing type 2 diabetes after delivery [3]. However, a large percentage of GDM are undiagnosed, and prevalence of postpartum type 2 diabetes is unknown, especially in developing countries [4]. In our regions, the data considering the incidence and the occurrence time-limit of diabetes after GDM is low [5]. And yet, the implementation of strategy to screening glycemic disorders in women with a history of GDM could lend support to reduce the important progression and diagnosis delay to diabetes in Africa [6].

Therefore, a prospective cohort study, in continuity with the screening and management protocol of GDM, has been initiated at the Endocrinology/Diabetology Department of Pikine National Hospital Center in Dakar (Senegal). The main purpose of this study was to outline postpartum glucose status among women with history of GDM, in Dakar hospitals' environment. Secondary aims included to point out the prevalence of postpartum diabetes and to identify factors influencing its occurrence.

\section{Methods}

\subsection{Study Design}

We conducted a prospective, descriptive and analytical study between January 1 , 2013, and July 31, 2018. This study included women over 18 years old who were diagnosed with a GDM during their last pregnancy criteria, according to IADPSG $2010 \mathrm{a}$ [7] and admitted at least 6 weeks postpartum. The patients on whom fasting plasma glucose (FPG) in the first trimester of the last pregnancy (routine FPG) was greater than or equal to $1.26 \mathrm{~g} / \mathrm{L}$ and patients experiencing a new pregnancy were not included in the study. Women with known diabetes were excluded.

Several strategies were implemented to motivate patients to return for their postpartum glucose testing. These features:

- Appointment for a postpartum diabetic consultation at the last prenatal consultation and/or at discharge out of the maternity unit.

- Phone calls.

- Short messaging system (SMS).

\subsection{Glucose Testing}

The blood glucose tests performed were essentially fasting plasma glucose (FPG) or oral glucose tolerance test (OGTT)/75 g using $250 \mathrm{ml}$ of a $30 \%$ glucose solution.

In involved women, glycemic disorders screening was preferably performed during the period range from the $6^{\text {th }}$ to $12^{\text {th }}$ week postpartum (early screening) or beyond (late screening). The findings of the blood glucose tests and other postpar- 
tum data (weight, body mass index (BMI), blood pressure, breastfeeding) in addition to the previous pregnancy related-data were subsequently collected in a form.

The diagnosis of diabetes and prediabetes was based on the 2006 World Health Organization (WHO) criteria [8].

\subsection{Statistical Analysis}

We used IBM SPSS Statistics for Windows, Version 20.0 (IBM Corp., Armonk, NY) for statistical analyses. Continuous variables were presented as means and standard deviation. Categoric variables were presented as proportions. For the analytical study, the patients with abnormal postpartum glucose values (diabetes and prediabetes) were compared with those normoglycemic using the Fisher exact test. A $p$-value of $<0.05$ was considered statistically significant.

\section{Results}

Overall, we included 53 women who met the criteria for our study.

\subsection{Epidemiological Characteristics and History of Included Patients}

The mean age of our patients was $32.64 \pm 5.28$ years with extremes range from 22 to 43 years. Multiparity found in $79 \%$ of cases. Twenty-nine (54.71\%) of them reported a family history of diabetes.

\subsection{Course of Previous Pregnancy}

In our study, all the included patients had a history of GDM. The diagnosis of GDM is based on routine fasting plasma glucose (FPG) and/or OGTT. This diagnosis is established before week 24 of pregnancy in $27.1 \%$ of the cases.

Excessive gestational weight gain $(>8 \mathrm{~kg})$ was noted in $24.5 \%$ of the cases. Gestational high blood pressure and preeclampsia was found in 8 patients. Women who had a urinary and/or vaginal infection during their pregnancy represented $50.9 \%$ of our cohort. Insulin therapy was required in 9 patients. The delivery rate by Caesarean Section was estimated at $42.3 \%$. Fetal macrosomia was noted in 3 newborns of mothers with GDM. The Apgar score was less than 7 at the $1^{\text {st }}$ minute for 3 babies. One case of neonatal death from unspecified cause was reported.

\subsection{Postpartum Patients Characteristics}

In our study, the patients admitted in postpartum period had a mean BMI of 27.90 $\mathrm{kg} / \mathrm{m}^{2} \pm 4.60$. Fifty percent of these patients had a BMI greater than $25 \mathrm{~kg} / \mathrm{m}^{2}$. Mean blood pressure was $121.95 \mathrm{mmHg} \pm 11.16$ for systolic and $78.28 \mathrm{mmHg} \pm$ 8.87 for diastolic. High blood pressure was found in $7.5 \%$ of the cases. All patients had chosen to breastfeed for at least 6 months, except one.

\subsection{Postpartum Glucose Testing}

The assessment of postpartum blood glucose status was performed in 53 of the 76 women who presented a GDM in our department during this period, corresponding to a postpartum screening rate of $69.70 \%$. 
Patients who underwent a screening in the first year after delivery accounted for $54.70 \%$ of the study population, $58.62 \%$ of whom were checked between the $6^{\text {th }}$ and $12^{\text {th }}$ week postpartum. The remaining included women were checked after the first year after delivery (Figure 1).

In $94.3 \%$ of cases, the assessment of postpartum blood glucose status was based on FPG. It was estimated on average at $0.99 \mathrm{~g} / \mathrm{L} \pm 0.17$ with extremes range from 0.62 to $1.35 \mathrm{~g} / \mathrm{L}$. In 3 patients, an OGTT/75 g glucose was performed between the $6^{\text {th }}$ and $12^{\text {th }}$ week postpartum.

\subsection{Prevalence of Postpartum Glycemic Disorders}

This screening strategy identified 11 cases $(20.7 \%)$ of abnormal postpartum glucose values (Figure 2). Type 2 diabetes after GDM was diagnosed in 6 patients, with a prevalence of $11.32 \%$. Impaired Fasting Glucose (IFG) was found in 5 patients (9.43\%). There were no cases of Impaired Glucose Tolerance (Figure 2).

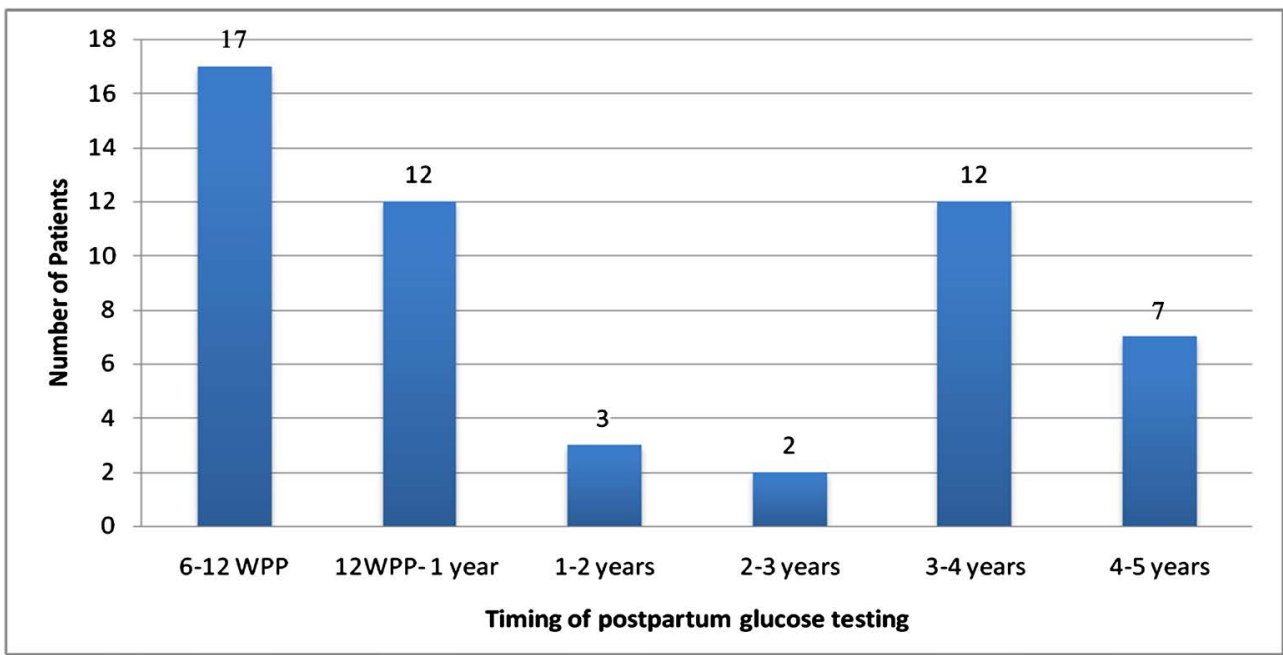

WPP: weeks postpartum.

Figure 1. Distribution of patients according to the timing of post partum glucose testing.

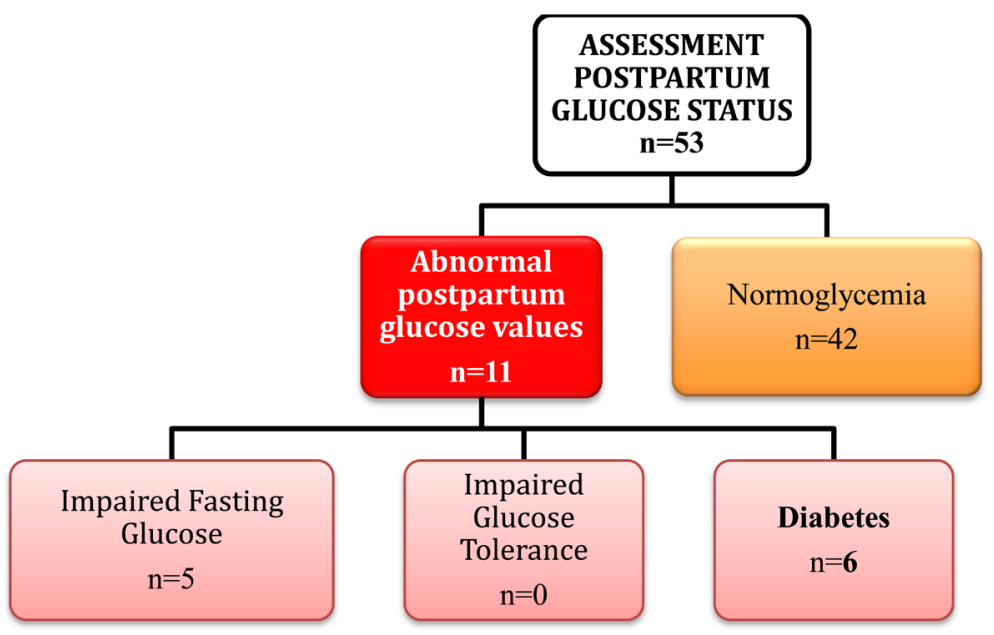

Figure 2. Distribution of included patients according to postpartum glycemic status. 


\subsection{Analytical Study}

Patients with an abnormal postpartum glucose rate had a mean age and BMI greater than those with normal blood glucose levels (Table 1). The correlation between "classic" predictors of the diabetes occurrence after GDM and postpartum blood glucose status in our patients is presented in Table 2 .

Multiparity was found in all patients with a postpartum glycemic disorders ( $p$ $=0.093$ ).

Insulin usage in the previous pregnancy was highly associated with the risk of postpartum diabetes in our patients $(p=0.05)$.

Patients' distribution according to the postpartum screening period and the glucose status is showed in Figure 3. Among the 6 cases of post-partum diabetes outlined in our study, 3 were diagnosed in the first year after delivery, the other 3 cases in the $3^{\text {rd }}, 4^{\text {th }}$ and $5^{\text {th }}$ year postpartum respectively. There was no statistically significant relationship between the timing of postpartum diabetes screening and blood glucose status. Considering the screening period of 6 - 12 weeks postpartum as a reference, the values were: 0.06 (12 weeks postpartum-1 year); 1 (1 - 2 years); 0.1 ( 2 - 3 years); 0.4 ( 3 - 4 years); 0.2 ( 4 - 5 years), respectively.

Table 1. Mean age of included patients regarding the postpartum glucose status.

\begin{tabular}{lcc}
\hline \multicolumn{1}{c}{ Means/standard deviation } & Age & BMI \\
Postpartum glucose status & 32.50 years \pm 5.46 & $26.88 \mathrm{~kg} / \mathrm{m}^{2} \pm 4.21$ \\
\hline Normoglycemia & 32.80 years \pm 3.56 & $30.38 \mathrm{~kg} / \mathrm{m}^{2} \pm 4.60$ \\
Impaired Fasting Glucose & & \\
Diabetes & 33.50 years \pm 5.89 & $32.27 \mathrm{~kg} / \mathrm{m}^{2} \pm 5.85$ \\
\hline
\end{tabular}

BMI: Body Mass Index.

Table 2. Correlation between "classic" predictors of the diabetes occurrence after GDM and postpartum blood glucose status in our patients.

\begin{tabular}{ccccc}
\hline & $\begin{array}{c}\text { Number of } \\
\text { Patients }(\mathbf{n}=53)\end{array}$ & $\begin{array}{c}\text { Abnormal postpartum } \\
\text { glucose values }(\mathbf{n}=11)\end{array}$ & $\begin{array}{c}\text { Normoglycemia } \\
(\mathbf{n}=\mathbf{4 2})\end{array}$ & $p$ \\
\hline Age $\geq 35$ ans & 22 & 5 & 17 & 1 \\
Multiparity & 42 & 11 & 31 & 0.09 \\
BMI $\geq 25 \mathrm{~kg} / \mathrm{m}^{2}$ & 37 & 9 & 28 & 0.47 \\
HBP & 8 & 1 & 7 & 1 \\
Family history of diabetes & 29 & 7 & 22 & 0.73 \\
$\begin{array}{c}\text { Diagnostic GDM before } \\
24^{\text {th }} \text { week of pregnancy }\end{array}$ & 7 & 2 & 5 & 0.62 \\
$\begin{array}{c}\text { Insuline usage } \\
\text { during pregnancy }\end{array}$ & 9 & 4 & 5 & 0.05 \\
Macrosomia & 3 & 1 & 2 & 0.38 \\
\hline
\end{tabular}

HBP: High blood pressure. 


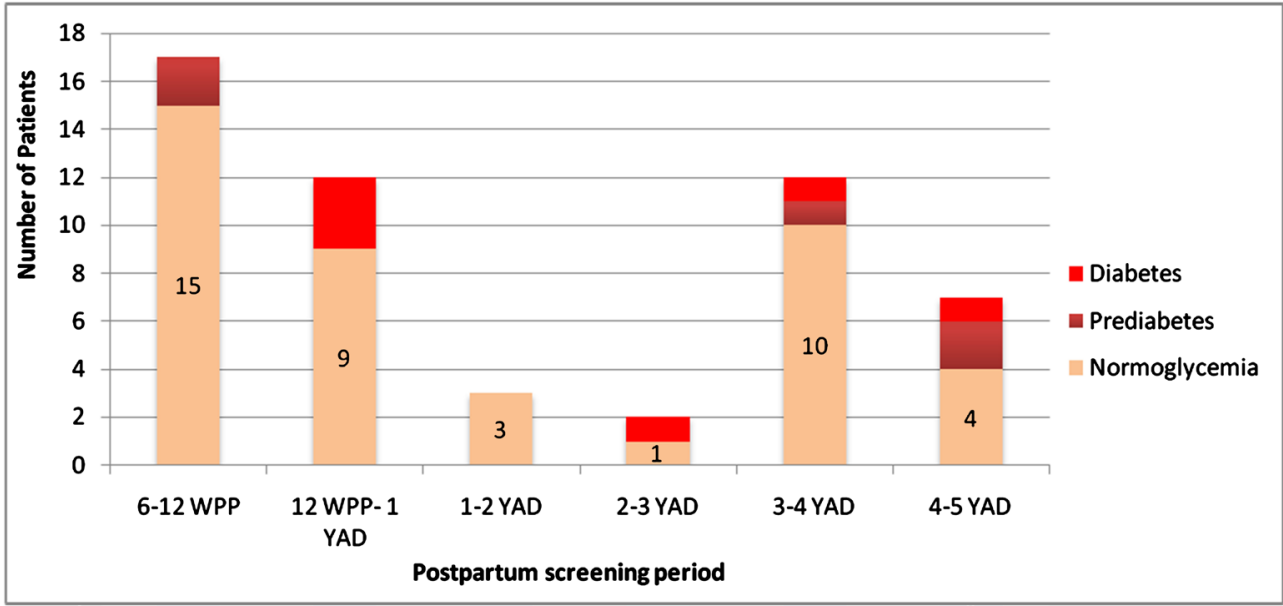

WPP: weeks postpartum; YAD: year after delivery.

Figure 3. Distribution of the patients according to the postpartum screening period and postpartum glycemic status.

\section{Discussion}

Women with history of GDM are at increased risk for diabetes [3]. Postpartum glucose testing is essential in screening women [3]. In the present prospective cohort study, postpartum glucose status was evaluated among women with GDM at Pikine National Hospital Center (Dakar, Senegal).

There were several obstacles to the systematic return of postpartum diabetic patients in our context. These featured lack of financial means, lack of time (multiparous, breastfeeding), apprehension of blood glucose test findings, and lack of knowledge of the risk of progression to type 2 diabetes for both patients and the medical staff [4]. Despite these issues, we performed a post-partum screening for about $70 \%$ of the women who presented a GDM diagnosed in our department during this period. This relatively good rate was the result of a communication and motivation strategy to encourage patients to have their blood glucose levels checked after delivery. As a result of these awareness campaigns, the postpartum return rate has increased significantly in recent years in several countries [2] [9].

In our study, the hospital prevalence of postpartum diabetes was $11.32 \%$ and that of impaired fasting glucose pattern was $9.43 \%$. This prevalence is close to the one reported by post-HAPO study, which found a prevalence of $11 \%$ regarding diabetes after a GDM meeting the IADPSG criteria [10]. The proportion of women with abnormal glucose tolerance at postpartum ranges between $20 \%$ to $60 \%$ [11]. This rate is influenced by many factors: ethnicity, diagnostic criteria of GDM, timing of postpartum glucose testing, postpartum screening methods.

OGTT should be the investigation of choice in the postnatal assessment of women who have had GDM [12]. Consensus guidelines continue to recommend this method despite persistent reports that only $35 \%$ of women complete the test [13]. In our study, it was performed in only 3 cases because it is an expensive and restrictive test with a lower tolerance level. Alternative testing method involving FPG or glycated haemoglobin (HbAlc) that bypass patient barriers show 
promise for improving the diagnosis of post pregnancy dysglycemia [13]. Thus, we had essentially used FPG, which was easier and more accessible for our patients.

According to the multicentre IMPACT study, glycemic disorders screening should be carried out within 6 months postpartum [14]. It is also recommended before a new pregnancy. In our study, patients were checked in the first year after delivery in more than half of the cases. This early screening resulted in the diagnosis of $45 \%$ of the diabetic and prediabetescases. Moreover, patients with diabetes diagnosed within 2 to 5 years postpartum didn't have glucose testing and their glycemic disorder could be present at that period. This outlines the importance of early detection, especially at most in the first year after delivery. If this initial screening is unremarkable, the frequency of blood glucose testing will depend on the presence of postpartum diabetes predictive factors [13]. Several risk factors have been identified in the literature as being associated with developing diabetes after GDM [15]. In our study, only insulin usage during pregnancy was statistically correlated with the occurrence of postpartum diabetes. The use of insulin during GDM is indicative of elevated blood glucose levels during pregnancy. Insulin usage in pregnancy is a robust predictor of diabetes after GDM identified in several studies [12] [15] [16].

Other classic risk factors such as maternal obesity, advanced maternal age and multiparity were not significantly associated with the occurrence of abnormal postpartum glucose tolerance in our patients. The small size of our cohort, limiting statistical correlations, certainly explains this situation.

\section{Conclusion}

We conducted a prospective study evaluating the evolution of the glycemic state after GDM. To our knowledge, this is the first paper in our region. The main limitations of our work were the small size of the study population and the low rate of completion of the oral glucose tolerance test (OGTT). It emerges from this study that screening for postpartum diabetes in patients with GDM within the recommended period must be improved in our context. Raising awareness among pregnant women and medical personnel will improve the detection rate of glycemic disorders after GDM.

\section{Conflicts of Interest}

The authors declare no conflicts of interest regarding the publication of this paper.

\section{References}

[1] Muche, A.A., Olayemi, O.O. and Gete, Y.K. (2019) Prevalence and Determinants of Gestational Diabetes Mellitus in Africa Based on the Updated International Diagnostic Criteria: A Systematic Review and Meta-Analysis. Archives of Public Health, 77, 36. https://doi.org/10.1186/s13690-019-0362-0

[2] Hossain, N. (2016) Postpartum Management of Diabetes Pregnancy. Journal of Pakistan Medical Association, 66, S85-S87. 
[3] Poola-Kella, S., Steinman, R.A., Mesmar, B. and Malek, R. (2018) Gestational Diabetes Mellitus: Post-Partum Risk and Follow Up. Reviews on Recent Clinical Trials, 13, 5-14. https://doi.org/10.2174/1574887112666170911124806

[4] Nwose, E.U., Mogbusiaghan, M., Bwititi, P.T., Adoh, G., Agofure, O. and Igumbor, E.O. (2019) Barriers in Determining Prevalence of Type 2 Diabetes Mellitus among Postpartum GDM: The Research and Retraining Needs of Healthcare Professionals. Diabetology \& Metabolic Syndrome, 13, 2533-2539. https://doi.org/10.1016/j.dsx.2019.07.002

[5] Natamba, B.K., Namara, A.A. and Nyirenda, M.J. (2019) Burden, Risk Factors and Maternal and Offspring Outcomes of Gestational Diabetes Mellitus (GDM) in Sub-Saharan Africa (SSA): A Systematic Review and Meta-Analysis. BMC Pregnancy Childbirth, 19, 450. https://doi.org/10.1186/s12884-019-2593-Z

[6] International Diabetes Federation (2019) IDF Diabetes Atlas. 9th Edition, IDF, Brussels.

[7] Metzger, B.E., Gabbe, S.G., Persson, B., et al. (2010) International Association of Diabetes and Pregnancy Study Groups Recommendations on the Diagnosis and Classification of Hyperglycemia in Pregnancy. Diabetes Care, 33, 676-682. https://doi.org/10.2337/dc09-1848

[8] World Health Organization (2006) Definition and Diagnosis of Diabetes Mellitus and Intermediate Hyperglycemia. Report of a WHO/IDF Consultation. World Health Organization, Geneva.

[9] Ferrara, A., Peng, T. and Kim, C. (2009) Trends in Postpartum Diabetes Screening and Subsequent Diabetes and Impaired Fasting Glucose among Women with Histories of Gestational Diabetes Mellitus: A Report from the Translating Research into Action for Diabetes (TRIAD) Study. Diabetes Care, 32, 269-274. https://doi.org/10.2337/dc08-1184

[10] Cosson, E. (2017) Gestational Diabetes Mellitus: Outcomes of Mothers after Pregnancy and Their Children. Médecine des Maladies métaboliques, 11, 518-524.

[11] Fatin, A. and Alina, T.I. (2019) Proportion of Women with History of Gestational Diabetes Mellitus Who Performed an Oral Glucose Test at Six Weeks Postpartum in Johor Bahru with Abnormal Glucose Tolerance. The Malaysian Family Physician, 14, 2-9.

[12] Leuridan, L., Wens, J., Devlieger, R., et al. (2015) Glucose Intolerance in Early Postpartum in Women with Gestational Diabetes: Who Is at Increased Risk? Primary Care Diabetes, 9, 244-252. https://doi.org/10.1016/j.pcd.2015.03.007

[13] Carson, M.P., Ananth, C.V., Gyamfi-Bannerman, C., Smulian, J. and Wapner, R.J. (2018) Postpartum Testing to Detect Persistent Dysglycemia in Women with Gestational Diabetes Mellitus. Obstetrics \& Gynecology, 132, 193-198. https://doi.org/10.1097/AOG.0000000000002687

[14] Bihan, H., Cosson, E., Vittaz, L., et al. (2014) Improving Postpartum Glucose Screening Following Gestational Diabetes Mellitus: The Impact Multicentre Initiative. Médecine des Maladies métaboliques, 8, 527-531.

[15] Rayanagoudar, G., Hashi, A.A., Zamora, J., et al. (2016) Quantification of the Type 2 Diabetes Risk in Women with Gestational Diabetes: A Systematic Review and Meta-Analysis of 95,750 Women. Diabetologia, 59, 1403-1411.

https://doi.org/10.1007/s00125-016-3927-2

[16] Coetzee, A., Mason, D., Hall, D.R. and Conradie, M. (2018) Prevalence and Predictive Factors of Early Postpartum Diabetes among Women with Gestational Diabetes in a Single-Center Cohort. International Journal of Gynecology \& Obstetrics, 142, 54-60. https://doi.org/10.1002/ijgo.12494 